\title{
Multiple myeloma and the challenges of its management in Nigeria
}

\begin{abstract}
Background: There is an increasing prevalence of Multiple Myeloma (MM) in Nigeria. Unfortunately, there is a poor awareness of this hematological disease among the healthcare providers and the targeted population in the country. The aim of this study is to highlight some of the challenges encountered in the management of MM in Nigeria.
\end{abstract}

Methods: By systematic literature search of previous publications on the management of MM in Nigeria using Google search engine, PubMed, MEDLINE, and the African Journal Online (AJOL) database.

Result: The awareness of MM is still very poor among healthcare providers. Case ascertainment is still a big issue due to diagnostic dilemma surrounding the disease. Most cases are seen by orthopedic surgeons only to present to primary physician (Hematologist) after complication must have set in. When diagnosis is made the definitive and supportive interventions are not readily available. The Hallmark is usually poor prognosis with a low survival interval ( $\leq 5 \%$ survive beyond 5 years post diagnosis).

Conclusion: Late diagnosis coupled with poor health determinants such as low SES, poor access to good health care, and lack of health-promoting policies that covers MM patients are major contributors of poor health outcome of people living with MM in Nigeria. There is a need to embark on a public health awareness campaign on MM in Nigeria. It is recommended that the government should make early detection, and healthcare coverage of people living with MM and other cancers topmost priority.

Keywords: multiple myeloma, management, challenges, nigeria, AJOL
Volume 6 Issue 4 - 2018

\author{
Ogbonna Collins Nwabuko',2 \\ 'Department of Hematology, Federal Medical Center, Nigeria \\ ${ }^{2}$ Department of Hematology, Abia State University, Nigeria
}

\section{Correspondence: Ogbonna Collins Nwabuko, Department of Hematology, FMC, Umuahia, Nigeria,}

Email ogbollins2002@yahoo.com

Received: April 18, 2018| Published: August 17, 2018

\section{Introduction}

Multiple myeloma (MM) is a cancer of plasma cells of blood in bone marrow which leads to overproduction of aberrant immunoglobulin in the blood, a condition known as paraproteinemia. It is one of the commonest hematological malignancies of public health importance in low-income countries of sub-Saharan Africa. It accounts for 10\%$15 \%$ of all lymphohematopoietic cancers, $1 \%$ of all cancer diagnosis and $0.9 \%-2 \%$ of all cancer-related deaths globally. ${ }^{1}$ It accounts for about $8.2 \%$ of hematological malignancies in Nigeria. ${ }^{2}$ The two major challenges in the management of MM in Nigeria are in the diagnosis and treatment. The duo is majorly responsible for the complications, poor prognosis and survival outcome of people living with $\mathrm{MM}$ in Nigeria.

\section{Method}

This article highlights some of the diagnostic and therapeutic challenges encountered by people living with multiple myeloma in Nigeria. A systematic literature search was carried out in Google, MEDLINE, PubMed, and the African Journals online (AJOL) database, with the aim of identifying relevant challenges in the diagnosis, staging, supportive and definitive therapeutic management of MM in Nigeria. The information was based on peer-reviewed articles published before December, 2017.

\section{Results and discussion}

\section{Aetiology, diagnosis and staging of MM in Nigeria}

The aetiology of multiple myeloma is unknown. However, Alexander (2007) experience as cited in Nwabuko et al., ${ }^{3}$ identified factors implicated as "potentially etiologic multiple myeloma risk factors". These factors include increasing age (>65years), male gender, black race, positive family history of multiple myeloma and the hypothesized precursors of multiple myeloma (i.e., Solitary Multiple Myeloma). Based on recent study in Nigeria, Africa's most populous black nation, the median age of diagnosis of Multiple myeloma was 59.9 years $(45-78 \text { years })^{4}$ while the male to female ratio was $2.3: 1 .^{5}$ However, there is paucity of study on the hypothesized precursors of multiple myeloma in Nigeria.

The diagnosis of multiple myeloma is based on a constellation of hematologic, immunologic, histologic, and radiographic features. A minimum of two major criteria, or one major criterion plus one minor criterion, or three minor criteria is used in making diagnosis of MM. ${ }^{6}$ The major criteria are plasmacytoma on tissue biopsy, bone marrow infiltration with $>30 \%$ BMPCs, monoclonal globulin spike on serum electrophoresis while the minor criteria include bone marrow infiltration with $10-30 \%$ BMPCs, paraprotein less than the defined quantity for major criteria and lytic bone lesion. The Table 1 below shows the criteria for diagnosis of MM. According to Nwabuko et al., ${ }^{4}$ "though primarily a disease of the bone marrow, it often poses a diagnostic dilemma for the orthopedic surgeons because of the frequent skeletal manifestations". It is usually misdiagnosed as an orthopedic disease when in the actual sense it is a hematologic disease with orthopedic complications. At advanced stage, it causes multiple lytic bone lesions with severe osteoporosis and pathological fracture. A previous observational study has shown that about $84.6 \%$ of newly diagnosed multiple myeloma patients in Nigeria present with multiple bone lesions, and end up with the orthopedic doctors, who may not suspect MM at the initial stage. ${ }^{3}$ The key players of the bone lesions in MM are cytokines namely IL-6 (Interleukin-6), TNFalpha (Tumor Necrosis factor), VEGF (Vascular Endothelial Growth 
Factor), PDGF (Platelet Derived Growth Factor) and IGF (Insulinlike Growth Factor). These cytokines, especially VEGF and PDGF have angiogenic effect on the bone marrow microenvironment and this effect favors the growth of myeloma cells in the bone marrow. A pilot study described the roles of these cytokines in bone tissue destruction and the effect of Zoledronic acid (a bisphosphonate) in their chemical behaviors in MM patient. ${ }^{7}$ Other complications such as anemia, nephropathy and constipation accounted for $61.5 \%, 23 \%$ and $19 \%$ in newly diagnosed MM patients in Nigeria. ${ }^{4}$

Table I Criteria for the diagnosis of MM

\begin{tabular}{|c|c|}
\hline Criteria & diagnosis of MM \\
\hline \multirow[b]{3}{*}{$\begin{array}{l}\text { Major } \\
\text { criteria }\end{array}$} & Plasmacytoma on tissue biopsy \\
\hline & Bone marrow infiltration with $>30 \%$ BMPCs \\
\hline & $\begin{array}{l}\text { Monoclonal globulin spike on serum electrophoresis } \\
(\mathrm{IgG}>35 \mathrm{~g} / \mathrm{L} \text { and } \operatorname{Ig} \mathrm{A}>20 \mathrm{~g} / \mathrm{L}) \text { or on concentrated urine } \\
\text { electrophoresis }(>1 \mathrm{~g} / 24 \mathrm{~h} \text { or kappa or lambda light chain) } \\
\text { (paraprotein) }\end{array}$ \\
\hline \multirow{4}{*}{$\begin{array}{l}\text { Minor } \\
\text { criteria }\end{array}$} & Bone marrow infiltration with $10-30 \%$ plasma cells \\
\hline & Paraprotein less than the level defined earlier \\
\hline & Lytic bone lesions \\
\hline & Normal $\operatorname{IgM}<0.5 \mathrm{~g} / \mathrm{L}, \operatorname{IgA}<1 \mathrm{~g} / \mathrm{L}$ or $\operatorname{IgG}<6 \mathrm{~g} / \mathrm{L}$ \\
\hline
\end{tabular}

Abbreviations: MM, multiple myeloma; BMPC, bone marrow plasma cell; IgG, immunoglobin $G$; IgA, immunoglobin A; IgM, immunoglobin $M$.

The staging of MM is another important step after diagnosis in the management of the disease. The essence of staging is for decisionmaking on therapeutic interventions and for prognostication of the disease. The Durie-Salmon (D-S) Clinical Staging System is used for staging MM. ${ }^{8}$ The D-S staging system has three stages (I, II, III) and two sub-classifications (A and B). The staging of MM is based on five parameters namely: the hemoglobin concentration, the serum calcium level, the skeletal X-ray of the bones, serum and urinary Immunoglobulin (paraprotein) quantification. The sub-classification A in the staging connotes "normal renal status" (i.e. no deranged serum creatinine level) while B connotes "abnormal renal state" (i.e. deranged serum creatinine level). Studies in Nigeria showed that most of the diagnoses of MM were made between Stages II-A and III-B. ${ }^{4,5,9,10}$ This late D-S stage at diagnosis contribute to the poor survival outcome of people living with MM in Nigeria. The Table 2 below shows DS Staging system. Although the D-S staging system is becoming obsolete in practice, the current method of staging MM is the International Prognostic Staging System (IPSS). This system using two parameters (serum albumin and beta- 2 microglobulin) in staging and prognosticating the outcome of MM. ${ }^{11}$ It is not commonly used in Nigeria because of the cost implication of the latter parameter.

\section{Supportive and definitive therapeutic intervention of $M M$ in Nigeria}

The last step in the management of multiple myeloma is the therapeutic intervention. The current standard treatment for MM is palliative care. This is a holistic treatment that offers supportive, definitive and psychosocial care for people living with MM. This is because of the life-threatening nature and the suffering associated with the disease. Recent studies in Nigeria showed that inadequate palliative care accounts significantly for the low survival interval of MM patients in Nigeria. The overall mean survival interval of MM patients in a Nigerian study was 39.7 months. From this study, only $7.6 \%$ of myeloma patients survive up to 5years post diagnosis. ${ }^{3}$

Table 2 DS staging system

\begin{tabular}{ll}
\hline Stages & DS \\
\hline & Hemoglobin $\geq 10.5 \mathrm{~g} / \mathrm{dL}$ \\
& Serum calcium normal \\
& X-ray showing normal bone structure or solitary bone \\
& plasmacytoma only \\
& Low paraprotein levels \\
All & IgG $\leq 50 \mathrm{~g} / \mathrm{L}$ \\
& IgA $\leq 30 \mathrm{~g} / \mathrm{L}$ \\
& Urinary light chain $\leq 4 \mathrm{~g} / 24 \mathrm{~h}$ \\
Fitting neither stage I or stage III & Hemoglobin $\leq 8.5 \mathrm{~g} / \mathrm{dL}$ \\
& Serum calcium $\geq 3 \mathrm{mmol} / \mathrm{L}$ \\
& Advanced lytic bone lesions (more than three lytic \\
& lesions) \\
& High paraprotein levels \\
& IgG $>70 \mathrm{~g} / \mathrm{L}$ \\
One or more & IgA $>50 \mathrm{~g} / \mathrm{L}$ \\
Urinary light chain $>12 \mathrm{~g} / 24 \mathrm{~h}$ \\
Sub-
\end{tabular}

Abbreviations: DS, Durie-Salmon; lgG, immunoglobin G; IgA, immunoglobin A.

The standard supportive care for MM patients at advanced stage of the disease which include the use of bisphosphonates, component blood therapy, antibiotics therapy, renal dialysis viz-a-viz renal transplant, radiotherapy, orthopedic care are grossly inadequate. Recent study showed that less than $40 \%$ of MM patients benefited from bisphosphonate therapy while only $3.8 \%$ benefited from radiotherapy which was offered outside the country. ${ }^{3}$ However, this was relatively lower than that from a similar study in Nigeria where about $45 \%$ of MM benefited from bisphosphonate. ${ }^{10}$ Safe blood transfusion practice in Nigeria is still at the rudimentary stage in most health centers. There was no beneficiary from component blood therapy in the study. All severely anemic cases that require blood transfusion benefited from either allogeneic whole blood transfusion $(50 \%)$ or the use of erythroid growth factor such as erythropoietin (38\%) while infection control was by use of antibiotic therapy/prophylaxis and colony stimulating unit-granulocyte (CFU-g) agents such as filgrastim.

In addition, the standard definitive interventions for people living with $\mathrm{MM}$ are anti-myeloma chemotherapy regimens and stem cell transplantation (autologous stem cell transplantation). The anti-myeloma chemotherapeutic regimens have undergone series of transformation and evolution over the years. Currently, what is in trend is the novel anti-myeloma therapeutic agent. These agents 
have the best effect in improving the quality of life and overall survival of MM patients. They have positively changed the course and paradigm of the disease in high-income countries. They include proteasome inhibitors (bortezomib, carfilzomib and ixazomib), immunomodulatory agents (thalidomide, lenalidomide), monoclonal antibody (elotuzumab, alantuzumab, rituximab) and HDAC inhibitors. Unfortunately, these agents are not readily available in low- and middle-income countries such as Nigeria. The limitations to their use in the region are cost and affordability. As a result of this, there is no consensus standard therapeutic treatment of MM in Nigeria. Majority of the anti-myeloma chemotherapy drugs used in the country are the old conventional alkylating agents such as melphalan (M), cyclophospamide and busulphan which are usually combined with a steroid (i.e. Prednisolone, P) as a double or triple-combination regimen. MP is still regarded as the standard of care for non-transplanteligible MM patients because of the cost and availability, long after it has been phased out for such role in developed countries. About $19.7 \%$ and $7.7 \%$ of the MM patients could afford triple combination regimens containing an immunomodulatory agent (thalidomide) and proteasome inhibitor (bortezomib) respectively. ${ }^{4}$ The only stem cell transplantation $(3.8 \%)$ was carried outside Nigeria and the patients died two years post-transplantation.

\section{Post diagnosis survival interval of $M M$ patients in Nigeria}

About $7.6 \%$ of MM patients survive up to 5 years post diagnosis in Nigeria. This is below estimated 5 years post diagnosis overall survival of $44.9 \%$ recorded by SEER cancer statistics review of 1975-2007 in the USA. The implication is that countries like the United States are over fifty years ahead of Nigeria in the management of MM. ${ }^{12}$

\section{Conclusion and recommendations}

Late diagnosis and poor therapeutic interventions are the hallmarks of poor prognostic and survival outcomes of MM in Nigeria. There is a need for awareness creation and provision of equipments for diagnosis and monitoring of MM patients in Nigeria. Definitive treatment of MM in Nigeria should be standardized by the consensus stakeholders in line with international best practices, while the drugs should be affordable and accessible at all locations in Nigeria. The public health system should, as a matter of urgency, provide insurance coverage for the management of $\mathrm{MM}$ and other cancer patients in Nigeria. A MM designated health center with state-of-art facilities for diagnosis and treatment (including radiotherapy machine) of MM should be situated at each of the six geo-political zones of Nigeria. This is the way forward in order to improve the quality of life of people living with $\mathrm{MM}$ and other cancers in Nigeria.

\section{Acknowledgements}

None.

\section{Conflict of interest}

The author declares that there is no conflict of interest.

\section{References}

1. Parkin DM, Bray F, Ferlay J, et al. Global cancer statistics. CA Cancer J Clin. 2005;55(2):74-108.

2. Landgren O, Kyle RA, Pfeiffer RM, et al. Monoclonal gammopathy of undetermined significance (MGUS) consistently precedes multiple myeloma. A prospective study. Blood. 2009;113(22):5412-5417.

3. Nwabuko OC, Igbigbi EE, Chukwuonye II, et al. Multiple myeloma in Niger Delta, Nigeria: complications and the outcome of palliative interventions. Cancer Manag Res. 2017;9:189-196.

4. Nwabuko OC, Nnoli MA, Igbigbi EE, et al. Plasma Cell Myeloma: Challenges in Diagnosis in sub-Saharan Africa. Jokull. 2015;65(1):254-266.

5. Omoti C, Halim NKD. Plasma cell myeloma in a Tertiary Center in Niger-Delta Region of Nigeria: clinico-immunologic analysis. Pak $J$ Med Sci. 2007;23(1):27-32.

6. Rajkumar SV, Kyle RA. Multiple myeloma: diagnosis and treatment. Mayo Clin Proc. 2005;80(10):1371-1382.

7. Annibali O, Petrucci MT, Tirindelli MC. Cytokines Behavior in Multiple Myeloma Patients during Zoledronic Acid Treatment. J Blood Lymph. 2017;7(4):184.

8. Durie BG, Salmon SE. A Clinical staging system for multiple myeloma: Correlation of measured myeloma cell mass with presenting clinical features, response to treatment and survival. Cancer. 1975;36(3):842-854.

9. Fasola FA, Eteng K, Akinyemi JO. Multiple myeloma: challenges of management in a developing country. J Med Med Sci. 2008;3(6):397-403.

10. Salawu L, Durosinmi MA. Myelomatosis: clinical and laboratory features in Nigeria. West Afr J Med. 2005;24(1):54-57.

11. Greipp PR, San Miguel J, Durie BG, et al. International staging system for multiple myeloma. J Clin Oncol. 2005;23(15):3412-3420.

12. Altekruse SF, Kosary CL, Krapcho M. SEER Cancer Statistics Review. 1975-2007. Bethesda: National Cancer Institute; 2010. 